\title{
O PROFESSOR-PESQUISADOR: UM SONHO QUE PODE SE TORNAR REALIDADE
}

\author{
Mariza Riva de Almeida e Déborah Scheidt ${ }^{1}$
}

\section{RESUMO}

Este trabalho vislumbra o professor no papel de realizador da "pesquisa-ação", uma categoria de pesquisa que envolve não só a investigação de um problema ou questão do âmbito da sala de aula, como também a tomada de um conjunto de atitudes objetivas que visam à modificação de práticas pedagógicas e à subseqüente resolução do problema.

Palavras-chave: Professor; Pesquisador; Pesquisa-Ação.

Se perguntarmos a vários professores de língua estrangeira se eles se vêem no papel de pesquisadores, a resposta da grande maioria provavelmente será negativa. A razão desse fato está na tradicional distância que sempre houve entre os papéis do professor e do pesquisador. O professor é tradicionalmente aquele que age na sala de aula, na tentativa de colocar em prática o que ele/ela aprendeu do pesquisador. O pesquisador, por outro lado, trabalha com as informações fornecidas pelo professor, ainda que ele/ela possa ter tido pouco contato real ou recente com o público alvo: os aprendizes.

Não existe uma justificativa plausível para essa separação. Acreditamos que todo professor pode e deve ser um pesquisador (e vice-versa), já que teoria e prática, quando aliadas, tendem a trazer resultados mais efetivos. ${ }^{2} \mathrm{O}$ primeiro passo nessa

\footnotetext{
${ }^{1}$ Mariza Riva de Almeida é mestre em Língua Inglesa e professora de Língua Inglesa do Departamento de Letras Estrangeiras Modernas da UFPR; Déborah Scheidt é mestre em Letras Literaturas de Língua Inglesa e professora no Centro Universitário Campos de Andrade (UNIANDRADE) e Faculdades Curitiba.

${ }^{2}$ De fato, a opinião algo inusitada de Dick Allwright e Kathleen BAILEY, é a de que o papel dos pesquisadores profissionais deveria ser idealistamente, o de consultores locais no sistema escolar, do mesmo modo como temos psicopedagogos "de plantão" exercendo funções de auxílio aos
} 
direção talvez esteja em mostrar ao professor que ele é um pesquisador por natureza, ou seja, que ele pode mudar a imagem que faz de si mesmo.

Na relação a seguir estão listadas algumas pressuposições sobre o trabalho de um pesquisador. De acordo com uma visão tradicionalista o pesquisador é aquele que:
a) É especialista em metodologia de pesquisa;
b) Tem conhecimento formal de estatística;
c) Leu extensivamente sobre o assunto em questão e
c) É capaz de utilizar-se de mecanismos sofisticados de coleta de dados.

Poucos professores conseguiriam descrever-se como pesquisadores levando em conta critérios como esses, um tanto quanto técnicos, rígidos e excludentes. A lista abaixo, por outro lado, revela características comuns a muitos professores que conhecemos. Entre elas podemos citar:
a) Experiência prática sobre os mecanismos de ensino e aprendizagem;
b) Consciência sobre problemas recorrentes na sala de aula;
c) Poder de reflexão;
d) Poder de questionamento;
e) Poder de resolução de problemas;
f) Criatividade.

$\mathrm{Na}$ verdade, as habilidades acima são tão válidas para um profissional da pesquisa quanto as da primeira lista. Se pensarmos em um episódio problemático qualquer de nossas vidas diárias, associando nosso comportamento subseqüente aos parâmetros da segunda lista, chegaremos à conclusão de que somos todos

\footnotetext{
professores. Nessa estrutura escolar, os professores poderiam recorrer aos pesquisadores, quando precisassem de uma opinião mais técnica sobre um assunto em particular. A vantagem principal seria a reversão do indesejado padrão atual em que os pesquisadores inventam" suas próprias teorias e somente então procuram os professores para colocá-las em prática. (1991, p. 198)
} 
pesquisadores. Ao pensarmos em nossas atitudes frente a uma dificuldade recente, provavelmente teremos percorrido as seguintes etapas:

a) Consideramos o conjunto de informações que caracterizaram o problema;

b) Elaboramos, mentalmente, algumas táticas para tentar saná-lo;

c) Consideramos uma mudança de comportamento;

d) Executamos tal decisão, ou talvez optamos por não executá-la, retornando, assim, para o item "b".

Algumas pessoas poderiam questionar a validade científica do processo acima. Ele poderia ser verdadeiramente classificado como "pesquisa"? Recorrendo à acepção geralmente aceita do termo, "pesquisa" pode ser definida como "um processo sistemático de investigação que consiste de três elementos ou componentes: (1) uma pergunta, problema ou hipótese; (2) dados e (3) análise ou interpretação desses dados." (NUNAN, 1993, p. 42). A tradução é de nossa responsabilidade.

Assim sendo, o processo descrito acima inclui não somente uma investigação de dados visando a sanar um problema, ou seja, uma pesquisa, - como vai além, apontando para uma categoria de pesquisa que objetiva a modificar algo que não vai bem - temos aí uma definição bem básica para PESQUISA-AÇÃO.

O termo "pesquisa-ação" vem sendo freqüentemente mencionado na área do ensino de línguas estrangeiras e esse interesse é fruto da história recente da evolução do ensino em geral. Estamos passando por uma mudança de paradigmas, como bem conclui FRAHM (2000), em que a "era do método" está dando lugar à "era da educação pedagógica". Em décadas passadas preconizava-se que um professor deveria "reverenciar" uma ou outra metodologia que seria capaz de proporcionar respostas a todo e qualquer questionamento relacionado ao seu ambiente profissional. As soluções ditas "válidas" seriam aquelas vindas de fora, ditadas pelo último modismo em ensino de línguas (tradução e gramática, audiolingualismo, método comunicativo, etc...).

Hoje, afora a crença de que diferentes métodos podem e devem ser utilizados em diferentes situações, o que vem sendo mais e mais levado em conta é o fato de que, 
além dos conceitos recebidos de fora, os professores podem trabalhar teorias criadas por si próprios. Essas teorias "pessoais" estão começando a ser vistas de modo tão positivo quanto as teorias "oficiais" e os professores, portanto, deveriam ser encorajados a refletir mais sobre suas próprias idéias e conceitos. Nessa perspectiva a solução para as mais diversas questões didáticas pode estar em cada um de nós. Essa espécie de atuação auto-analítica tem sido classificada sob o rótulo de "práticas reflexivas".

Algumas práticas reflexivas incluem a participação em experiências de aprendizado de línguas, em que o professor tenta ver as coisas pela ótica do aluno, ou a rememoração de experiências passadas, quando professor procura lembrar-se de seu próprio contato inicial com a língua estrangeira em questão. Práticas exploratórias e pesquisa-ação também podem ser incluídas aqui. São conceitos bastante similares, já que ambos envolvem práticas investigativas em sala de aula iniciadas pelo professor. A grande diferença é que o segundo conceito é mais abrangente. Além da pesquisa ele pressupõe a resolução de um problema. Ao contrário, porém, do que costuma ocorrer com a vida diária, na sala de aula, qualquer que seja a prática reflexiva escolhida, esta só trará resultados satisfatórios se for realizada de modo sistemático.

Diferentes autores sugerem roteiros ligeiramente diferentes, porém com a auto-reflexão como elemento unificador de todo o processo. Levando em conta nossa experiência de trabalho no campo da pesquisa-ação com cerca de cinqüenta professores de inglês provindos principalmente do setor público do Estado do Paraná, gostaríamos de apresentar um modelo de como realizar a pesquisa-ação, proposto por David NUNAN (1994, p. 18-19), um dos precursores desse tipo de estudo voltado para o ensino de línguas estrangeiras. Subseqüentemente apresentaremos nossos próprios comentários e sugestões, no intuito de mostrar como o modelo de Nunan pode ser adaptado às necessidades e ao contexto de nossos colegas brasileiros. Por último, apresentaremos um exemplo de pesquisa-ação realizado por uma de nossas orientandas.

Nunan sugere o seguinte conjunto de atitudes para a realização da pesquisaação: 
$\mathbf{1}^{0}$ PASSO: Identifique uma questão que possa estar trazendo dificuldades na sua prática pedagógica;

$\mathbf{2}^{\mathbf{0}}$ PASSO: Realize a coleta dos dados preliminares;

$3^{\mathbf{0}}$ PASSO: Formule uma hipótese;

$4^{0}$ PASSO: Realize as mudanças necessárias;

$5^{\circ}$ PASSO: Avalie os efeitos das mudanças;

$6^{0}$ PASSO: Compartilhe suas conclusões com outros colegas.

$\mathbf{7}^{\mathbf{0}}$ PASSO: Planeje outras intervenções.

Você pode achar conveniente dedicar algum tempo antes do $1^{o}$ passo observando suas aulas e refletindo para poder determinar qual será o objeto mais pertinente para sua investigação. Aqui estão alguns exemplos populares de tópicos de pesquisa sugeridos pelos professores com os quais trabalhamos:

- Grande número de alunos por classe;

- Grande desnível na habilidade lingüística dos alunos;

- Os alunos não compreendem o propósito de estudar uma língua estrangeira;

- A aula é mais centrada no professor do que nos alunos;

- Os alunos sentem-se envergonhados em se expressar em língua estrangeira;

- O professor gostaria de usar mais a língua estrangeira durante a aula.

Apesar de estarmos propondo algumas sugestões, o professor deve estar consciente de que o processo de investigação deve ser significativo para sua realidade específica e que ele/ela é quem vai se beneficiar mais se a pesquisa for adequada às suas necessidades. Muitos dos relatórios de pesquisa-ação que recebemos estavam centrados no aluno, porém de uma maneira negativa, isto é, os professores escolheram investigar por que os alunos tinham dificuldades em determinados conteúdos. Poucos professores chegaram a questionar sua própria atuação em sala de aula. Um bom exemplo desse equívoco é o de uma professora que em seu relatório descreveu 
extensivamente como seus alunos não gostavam de gramática e a consideravam difícil de compreender. Quando analisamos seu relato com mais atenção, percebemos, nas entrelinhas, que ela própria tinha uma impressão negativa quanto à gramática, apesar de nunca ter mencionado diretamente esse "pequeno" detalhe. A lição que podemos tirar desse episódio é a de que tentar enganar a si próprio é o pior dos equívocos.

O segundo passo também requer um período de preparação. Primeiramente é necessário decidir sobre o melhor modo de se coletar os dados. Os instrumentos de coleta podem variar de uma observação mental minuciosa, anotações escritas, perguntas abertas (orais ou escritas), ou de múltipla escolha colocadas diretamente aos alunos, etc. O professor pode também recorrer a um gravador de áudio (visível ou não) ou câmera de vídeo. Porém se o professor perceber que está demasiadamente envolvido(a) na situação para chegar a uma conclusão objetiva sobre seu comportamento ou o comportamento de seus alunos, uma opção é convidar um colega para realizar a observação. O importante é que o professor perceba que a iniciativa pela pesquisa-ação deve ser tomada por decisão própria. Nesse caso a observação da aula é bem diferente daquela sugerida por um Supervisor, Coordenador ou Diretor. Outro detalhe a ser decidido é a quantia de tempo a ser despendida com a coleta de dados, que pode durar uma ou duas aulas em alguns casos (Ex.: Como fazer com que todos os alunos queiram participar quando faço uma pergunta?), ou muito mais tempo (todo um período letivo, suponhamos), se o professor estiver investigando, por exemplo, se uma nova técnica de aquisição de vocabulário é realmente eficiente.

Com todas as informações preliminares à disposição, chegou o momento de passar para o terceiro passo, e tentar pensar numa possível solução para o problema. Aqui vai um exemplo de hipótese em pesquisa-ação: "Se eu escrever os objetivos e os passos de minha aula claramente no quadro, não perderei mais tanto tempo tentando fazer com que os alunos compreendam as instruções quando passo de um estágio a outro da lição" (veja exemplo de projeto de pesquisa-ação abaixo).

O quarto passo é crucial neste tipo de trabalho. A palavra chave é mudança, que nem sempre é um passo fácil, mesmo quando a necessidade da "inovação" parece bastante óbvia. Um bom exemplo disso é o relatado por uma professora bastante 
insegura em adotar mais atividades em duplas e em grupos numa classe de 45 adolescentes. Ela temia o alto volume das "conversas" na sala, mesmo sabendo que seu objetivo primário era melhorar a comunicação oral dos alunos.

Uma atitude mais radical é o que a Professora Jeffra FLAITZ, da Universidade de South Florida, U.S.A. costuma chamar de "walk on the wild side" (algo como "dar um passeio no lado selvagem da floresta"). Essa tática consiste em fazer algo que vai completamente contra seus hábitos rotineiros e características pessoais, e que, numa situação normal lhe deixaria assustado ou envergonhado. Um exemplo: se você é um professor bastante falante e seu problema é que sua aula acaba sendo centrada em seu próprio discurso e não o dos alunos, você poderia desafiar seus próprios impulsos e tentar passar uma aula inteira sem falar uma só palavra. Você poderia chegar à conclusão que os alunos podem sobreviver e até mesmo aprender sem sua permanente voz para guiá-los. Em resumo: seja criativo e audacioso.

Ao realizar o quinto e o sexto passo o professor descobrirá se será necessário passar pelo sétimo passo (que implicaria retornar ao terceiro) ou se já é possível declarar a pesquisa concluída com sucesso. Lembre-se que é muito importante compartilhar suas conclusões com seus colegas, para que todos possam se beneficiar das COMPETÊNCIAS específicas uns dos outros.

Para ilustrar a praticabilidade e a eficiência do que foi exposto, relatamos, a seguir, um exemplo de trabalho de pesquisa-ação realizado durante um dos cursos que ministramos sobre o assunto. Num artigo de pesquisa-ação nada melhor do que valorizar os resultados e a cooperação profissional. Portanto ficamos honradas e agradecidas em fazer da conclusão da colega Vera Miguel o nosso próprio fechamento.

\section{PRATICANDO A PESQUISA-AÇÃO}

Vera Lucia Moraes Miguel

Núcleo de Assessoria Pedagógica (NAP), UFPR, 1999 


\section{INTRODUÇÃO}

Sou professora de inglês em uma escola pública desde 1980. Ao planejar este trabalho, iniciei uma série de reflexões sobre minhas práticas pedagógicas e cheguei à conclusão que a maioria dos professores, dentre eles eu mesma, são eternos pesquisadores, até mesmo quando não estão conscientes desse fato, já que estão sempre questionando seu trabalho, testando novas metodologias e materiais, desenvolvendo novas atitudes para com os alunos e engajando-se em diversas atividades de desenvolvimento profissional.

\section{$1^{0}$ passo: Identificação do problema}

Ao investigar minha prática pedagógica percebi, logo de início, o grau do desafio em definir um problema a ser pesquisado. Como classificar, contando somente com minha experiência e intuição, a relevância de cada um de meus problemas em sala de aula? Com isso sempre em mente, comecei a observar mais atentamente a ambientação de minhas classes. Dentre as muitas dificuldades rotineiras, um fato chamou-me a atenção e tentei, então, visualizá-lo em termos operacionais: observei que havia em minhas aulas, de modo recorrente, um período de agitação entre uma atividade e outra. Os alunos pareciam ficar perdidos no momento entre o término de uma atividade e o início de outra. Eles não pareciam conscientes de que era hora de passar para um novo estágio, assim como uma pessoa que termina o prato principal de uma refeição e, enfastiada, considera tudo o que vem depois como um mero complemento. O que estava ocorrendo? Como eu poderia descobrir por que meus alunos não demonstravam o mesmo nível de entusiasmo para todas as atividades propostas?

\section{$2^{\circ}$ passo: Coleta de dados}

Percebi que não estava preparada para agir imediatamente. Minha experiência e a literatura técnica a que recorri me diziam que eu devia selecionar uma estratégia adequada e organizar meus questionamentos para, somente então, encontrar uma 
solução para o problema. Descobri logo de início que isso não era tão simples, já que eu estava tratando com seres humanos.

Decidi então, redigir um diário detalhado com os acontecimentos de cada aula, como também um relato de meus sentimentos face a eles. Simultaneamente também resolvi gravar em áudio-cassete algumas de minhas aulas com o intuito de apreender melhor minhas próprias atitudes e respostas.

\section{$3^{\circ}$ passo: Formulação de uma hipótese}

Finalmente, formulei as seguintes perguntas:

- Comunico as novas atividades com clareza aos alunos?

- As atividades têm um início e um fim bem definidos?

- O que posso fazer para conscientizar os alunos sobre a importância de cada atividade?

Elaborei então um plano de aula baseada nas questões acima e na hipótese de que se eu conseguisse "visualisar" melhor os intervalos entre uma atividade e outra, poderia chegar a uma conclusão sobre como resolver o problema da desconcentração na minha classe.

O plano de uma aula de 50 minutos direcionava-se a 37 alunos da $8^{\text {a }}$ série (14 anos de idade). Os objetivos eram praticar "listening" e "reading comprehension", utilizando um tape com um texto sobre a vida dos coalas e o mesmo texto escrito (proveniente do livro didático dos alunos). As habilidades praticadas seriam "prediction", "listening comprehension", "scanning", "speaking" e "writing". Os alunos deveriam ouvir o tape e, simultaneamente, preencher as lacunas de uma tabela sobre a vida dos coalas. A aula envolveria as seguintes etapas: a) copiar as frases do quadro, ouvir o tape e preencher lacunas; b) abrir os livros e checar as respostas; c) ouvir a explicação da professora sobre a próxima atividade e dividir a turma em duplas; d) completar uma tabela; e) checar as respostas com outras duplas; f) corrigir as respostas oralmente com toda a turma. 
Iniciei então um diário escrito e uma rotina de auto-observação através de gravações em áudio, tentando achar respostas objetivas para os questionamentos acima. Ao ouvir as fitas, percebi que não estava fazendo exatamente o que pensava estar fazendo. Senti que minhas instruções não eram claras o suficiente para que todos os alunos as compreendessem. Também percebi que eu mesma tinha dificuldades em passar de uma atividade para outra com a desenvoltura necessária. Mesmo após ter terminado uma atividade, eu levava muito tempo para iniciar a próxima. Ou seja, eu não estava seguindo dois preceitos básicos para uma boa aula: utilizar eficientemente o tempo da aula e dar instruções claras.

Refleti criticamente sobre meu comportamento, sentindo todo o peso de admitir minhas próprias falhas, porém o mais importante é que eu tinha detectado (ou julgava ter detectado) o problema, e assim, poderia ter mais controle sobre ele. Ao examinar o material coletado novamente, percebi que tinha dificuldade em iniciar uma nova atividade porque ainda estava envolvida com a anterior, e, como não tinha uma idéia muito clara sobre o que fazer logo após, eu precisava parar e pensar sobre o próximo passo.

\section{$4^{0}$ passo: Realização das mudanças}

Nessa altura eu sabia que havia duas coisas a fazer: utilizar melhor o tempo de aula e dar instruções mais claras aos alunos. Planejei, então, algumas mudanças em minhas aulas:

a) Comecei a planejar as aulas mais sistematicamente, colocando no papel todos os passos que deveria seguir para não perder minutos preciosos;

b) Passei a determinar com antecedência os objetivos e a seqüência de atividades da aula e a sucintamente, escrevê-los no quadro no início de cada aula (Por exemplo, para a lição aqui descrita, colocaria no quadro a seguinte seqüência: 1. copiar, 2. ouvir, 3. preencher, 4.completar 5. corrigir);

c) Antes de dar qualquer instrução durante a aula, procurava me assegurar de que tinha a atenção de todos. Além disso, passei a enunciar as instruções mais cuidadosamente, de modo a que todos pudessem compreendê-las. 


\section{$5^{\mathbf{0}}$ passo: Avaliação dos efeitos das mudanças}

Mantive meu diário e após algum tempo comparei os registros iniciais sobre o comportamento dos alunos com os posteriores. Minhas aulas haviam melhorado muito, porém senti que poderia melhorá-las ainda mais.

\section{$6^{0}$ passo: Compartilhamento de idéias}

Através de reflexão e também de conversas com colegas, cheguei a uma nova e importantes modificação:

\section{$7^{0}$ passo: Planejamento de novas intervenções}

Assim que eu dava instruções, especialmente para atividades em duplas ou em grupos, os alunos imediatamente saíam das carteiras para encontrar o parceiro preferido, ou olhavam para os lados, procurando parceiros. Esse tipo de comportamento impedia que ouvissem as instruções atentamente, criando confusão e os subseqüentes problemas de interpretação. Estabeleci, assim, o seguinte comando: "Pay attention, don't move till I say the password and the password is GO!" Os alunos passaram a compreender que precisavam prestar atenção e não deviam iniciar a atividade até que todas as instruções fossem dadas e todas as dúvidas esclarecidas. Somente então eu dava o comando "GO".

\section{CONCLUSÃO}

A realização da pesquisa-ação contribuiu para que eu me tornasse mais organizada. Para estabelecer a sequiência de cada aula, passei a planejar meus procedimentos, de acordo com o tempo disponível, com muito mais cuidado. Acostumei-me a refletir sobre o modo mais efetivo de ensinar cada conteúdo e sobre os resultados que espero dos alunos, para só então determinar as atividades para cada etapa da aula.

Em resumo, fazer pesquisa-ação foi muito relevante para minha prática pedagógica. Ao realizar este trabalho, tornei-me muito mais consciente de minhas 
atitudes profissionais e passei a trabalhar de modo mais reflexivo e questionador. Percebo agora que existem muito mais detalhes envolvendo o ambiente de uma sala de aula do que julgava anteriormente. Os resultados de minha pesquisa são bastante simples, porém agora realmente me vejo como uma pesquisadora, acredito poder chegar a conclusões por minha própria conta e poder compartilhá-las com colegas. E o mais importante de tudo: descobri que a pesquisa-ação realmente funciona! 


\section{REFERÊNCIAS BIBLIOGRÁFICAS}

ALLWRIGH, D.; BAILEY, K. Focus on the language classroom: an introduction to classroom research for language teachers. Cambridge: CUP, 1991.

FRAHM, G. Change/innovation in formal education. Lancaster: Lancaster University, 2000.

NUNAN, D. Action research in language education. In: EDGE, J.; RICHARDS, K. (Eds.). Teachers develop teachers research: papers on classroom research and teacher development. Oxford: Heinemann, 1993. p. 39-50.

Research methods in language learning. Cambridge: CUP, 1994. 